\title{
Educação e Cibercultura: ensinar e aprender com as imagens digitais nos processos comunicacionais na/da internet
}

\section{Education and Cyberculture: teaching and learning with digital images in communication processes on/of the internet}

\begin{abstract}
Resumo: O texto apresenta parte dos resultados de pesquisa de mestrado recentemente concluída. O objetivo desenvolvido neste trabalho foi promover uma reflexão sobre os usos das imagens digitais nos processos comunicacionais na/da internet, e como as práticas pedagógicas poderiam se beneficiar das dinâmicas colaborativas e interativas da cibercultura. Para isso, busquei auxílio nas contribuições de autores que discutem a cibercultura a partir da ótica dos campos da comunicação e da educação, e na abordagem teórico-metodológica da etnografia virtual para compreender os fenômenos sociais e culturais das redes digitais. Considerando a ampliação dos processos comunicacionais para as interfaces digitais da $W e b$, concluí que seria interessante, enquanto educadores, estarmos atentos à reconfiguração das formas de ensinar e aprender que emergem na relação dos sujeitos com as imagens digitais.
\end{abstract}

Palavras-chave: Processos comunicacionais. Cibercultura. Imagens digitais. Educação.

\begin{abstract}
The text presents part of the results of a master's degree research recently completed. The objective developed in this work was to promote a reflection on the use of digital images in communicational processes on/of the Internet, and how pedagogical practices could benefit from the interactive and collaborative dynamics of cyberculture. Henceforth, I sought help in the contributions of authors that discuss cyberculture from the perspective of communication and educational fields, and in the theoretical-methodological approach of virtual ethnography to understand the social and cultural phenomena of digital networks. Considering the expansion of communicational processes to digital interfaces of the Web, I concluded that it would be interesting, as educators, that we are alert to the reconfiguration of the forms of teaching and learning that emerge in the relationship of subjects with the digital images.

Keywords: Communicational processes. Cyberculture. Digital images. Education.
\end{abstract}

COUTO JUNIOR, Dilton Ribeiro do. Educação e Cibercultura: ensinar e aprender com as imagens digitais nos processos comunicacionais na/da internet. Informática na Educação: teoria e prática, Porto Alegre, v. 18, n. 1, p. 37-50, jan./ jun. 2015.

\author{
Dilton Ribeiro do Couto Junior \\ Universidade do Estado do Rio de Janeiro
}

\section{Introdução}

Com a emergência das mídias digitais,

[...] pela primeira vez, qualquer indivíduo pode produzir e publicar informação em tempo real, sob diversos formatos e modulações, adicionar e colaborar em rede com outros [...] Os exemplos são numerosos, planetários e em crescimento geométrico: blogs, podcasts, sistemas peer to peer, softwares livres, softwares sociais, a arte eletrônica... Trata-se de uma crescente troca e processos de compartilhamento de diversos elementos da cultura a partir das possibilidades abertas pelas tecnologias eletrônico-digitais e pelas redes telemáticas contemporâneas (LEMOS, 2007, p. 36-37).

Neste cenário, que envolve uma grande quantidade de artefatos tecnológicos à disposição dos usuários, internautas hoje interagem 
na rede mundial de computadores. A liberação da palavra, discutida ao longo da obra de Lemos e Lévy (2010), revela a possibilidade dos internautas serem produtores e colaboradores ativos de conteúdos para a Web: de forma rápida e dinâmica, as informações são compartilhadas em sites de redes sociais, publicadas em blogs, jornais eletrônicos, dentre outras interfaces, tornando possível que outros usuários tenham a oportunidade de visualizá-las e comentá-las. Produtores ativos de informação que contribuem para a constante expansão e modificação da $W e b$, os internautas realizam a edição, manipulação, produção e compartiIhamento de todo e qualquer arquivo digital na infraestrutura interativa e participativa do ciberespaço.

Ao contrário das mídias massivas, nas quais o fluxo da informação se dá na perspectiva um-todos, nos processos comunicacionais mediados pelas mídias digitais em rede, há a possibilidade da comunicação todos-todos. Não há como desconsiderar que os sites de redes digitais vêm se constituindo como espaços privilegiados para que muitos jovens, hoje, exerçam a liberdade de expressão; exerçam a possibilidade de falar e de ouvir, de manifestar-se politicamente pelo que acreditam. Indo nessa mesma direção, Pretto mostra que

Desde o início desta última década, com a explosão do acesso à internet e ao barateamento dos equipamentos digitais, a produção de imagens e informações deixou de estar restrita aos grandes conglomerados midiáticos e passou a ser prerrogativa de qualquer um (PRETTO, 2013, p. 65).

A cibercultura nasce de uma apropriação tecnológica que vem modificando as relações cotidianas dos sujeitos (LEMOS, 2013). As tecnologias digitais em rede criam formas diversas de habitarmos as esferas do ciberespaço e das cidades, ampliando a nossa capacidade de produzir conhecimentos (SANTOS, 2011). Longe de ser compreendida como a cultura do ciberespaço, a cibercultura permite a rica troca na internet, principalmente a partir dos sites de redes sociais digitais. Com a emergência da Web 2.0, a rede mundial de computadores vem sofrendo grandes transformações com o passar dos anos e, segundo Santaella (2002, p. 53), "Quaisquer tentativas de predição em tempos tão tumultuados beiram o impossível. O que foi escrito sobre as redes em 1995, por exemplo, parece hoje tão distante a ponto de provocar o riso". Lemos e Lévy (2010) mostram que o termo Web 2.0 foi criado por Tim O'Reilly em 2004 com o objetivo de apontar a diferença em relação a Web 1.0. Na Web 2.0, os websites são mais abertos e interativos, possibilitando dinâmicas mais intensas de compartilhamento de arquivos. Essa característica da Web hoje propicia que, além do acesso à grande quantidade de informação, possamos também exercitar a aprendizagem colaborativa na e em rede, que está se desenvolvendo de maneira surpreendente e modificando a nossa relação com a Web (LEMOS; LÉVY, 2010).

Para Santaella (2013), as redes sociais da internet são as meninas dos olhos na Web 2.0, com intensas formas de comunicação entre internautas que, cada vez mais, estão interconectados e compartilhando diversos tipos de conteúdos criados por profissionais e pessoas amadoras. De acordo com a autora, "[...] o que fazemos com as redes sociais digitais não é tão importante quanto saber o que as redes estão fazendo conosco" (SANTAELLA, 2013, p. 34). Interagir na rede e em rede traz implicações, segundo Santaella, para as questões referentes à sociabilidade, à subjetividade, às formas de ensinar e aprender, às expectativas, aos nossos anseios, dentre outras, uma vez 
que modifica a forma como recebemos informações e adquirimos conhecimento na relação com o outro.

Este é o pano de fundo da dissertação de mestrado recentemente concluída. O objetivo a que me proponho desenvolver neste texto é o de promover uma reflexão sobre os usos das imagens digitais nos processos comunicacionais na/da internet. Parece muito importante que o campo da educação se debruce sobre as práticas sociais que emergem com a cibercultura, tendo em vista que "[...] a escola pode e deve intensificar o diálogo entre a cultura escolar e a cultura midiática ao oferecer oportunidades de produção de narrativas de autoria dos estudantes com o uso de novas linguagens e tecnologias" (OROFINO, 2005, p. 29). Em tempos de cibercultura, os internautas criam formas dinâmicas para interagir com seus pares, revelando a multiplicidade de pontos de vista e a percepção do mundo pela ótica do outro. Upload e download são palavras-chave de uma época em que se consome e se (re)produz grandes quantidades de informação. $\mathrm{Na}$ concepção de Martins e Couto Junior (2007), fornecer auxílio à compreensão de como os jovens atualmente se relacionam com os diversos artefatos tecnológicos é ensejar que processos de ensinar-aprender possibilitem 0 diálogo entre educadores e educandos no sentido de romper com o anacronismo da escola representado pela desconsideração a outras expressões culturais que não sejam a letrada. Afinal, como as práticas pedagógicas poderiam se beneficiar ao conhecer a relação dos jovens com as imagens digitais que circulam pela internet?

A fundamentação teórico-metodológica da pesquisa apoiou-se nas contribuições da et- nografia virtual (ou netnografia) ${ }^{1}$ e no diálogo com autores dos campos da comunicação e educação. A netnografia aponta que é possível conviver com os sujeitos em um novo locus de pesquisa, o ciberespaço. Este locus se constituiu, no meu caso, como um ambiente propício para legitimar e reconhecer o outro como legítimo outro na produção de conhecimentos que vem sendo, mais recentemente, exercida cotidianamente também pelos sujeitos nas redes sociais da internet. Amaral (2009) apropria-se da netnografia como uma metodologia que reconhece a alteridade e a coautoria, ressaltando principalmente a ideia do conhecimento ser construído em comunhão com o pesquisador.

Por ser a rede social que mais vem crescendo no Brasil, o Facebook foi adotado como campo empírico. Optei por escolher como sujeitos do estudo jovens que já faziam parte de minha rede de amigos no Facebook e outros que, no decorrer da investigação, se mostraram interessados em participar. Assim, eu trilhei os caminhos necessários para interagir com noventa e oito jovens com os saberes compartilhados na referida interface. Para realizar as análises das conversas on-line, optei por fazer uso de siglas para me referir aos jovens, preservando, desta forma, a identidade deles. O critério utilizado para selecionar, no Facebook, as informações produzidas e compartilhadas por mim e pelos sujeitos da pesquisa foi a popularidade das conversas on-line no Feed de notícias,

\footnotetext{
${ }^{1} \mathrm{O}$ foco deste texto não é apresentar e aprofundar questões teórico-metodológicas que emergem quando o ciberespaço é adotado como campo empírico. Para maiores informações sobre a netnografia, ver os trabalhos de Rocha e Montardo (2005), Amaral, Natal e Viana (2008), Amaral (2009), Gutierrez (2009), Mercado (2012), Santos e Couto Junior (2013) e Couto Junior (2013). Além disso, vale ressaltar que, de acordo com Amaral (2009), o termo netnografia tem sido mais utilizado pelos pesquisadores do marketing e da administração, enquanto o termo etnografia virtual é mais utilizado pelos pesquisadores da antropologia e das ciências sociais. O meu objetivo aqui não é discutir as especificidades dos termos mencionados, e ressalto que os utilizo como sinônimos.
} 
muitas das quais envolvendo o uso de arquivos de áudio e vídeo. Isso propiciou que houvesse o maior envolvimento e participação dos sujeitos da pesquisa nas conversas por nós tecidas no decorrer do estudo de campo, que ocorreu entre março de 2011 e março do ano seguinte. Os dados foram analisados à luz da fundamentação teórico-metodológica, principalmente a partir de autores que discutem as tecnologias digitais e as redes sociais da internet (LEMOS, 2005, 2007, 2009, 2010, 2013, SANTAELLA, 2002, 2010, 2013), bem como autores do campo da educação atentos às questões que emergem com as práticas sociais da cibercultura (SANTOS, 2002, 2011, ARRUDA, 2009).

A escolha do Facebook como campo empírico me possibilitou criar vínculos sociais e afetivos com os jovens no ciberespaço, que "[...] já fez da cultura um lugar de produção de conteúdo, de conexão livre entre pessoas e grupos e de reconfiguração da vida social, política e cultural" (LEMOS, 2010, p. 29). Lemos e Lévy (2010) também trazem uma discussão sobre a ideia de que o ciberespaço hoje apresenta maior liberdade de uso aos usuários, propiciando a comunicação em escala planetária pelas "[...] possibilidades de escrita coletiva, de aprendizagem e de colaboração na e em rede. Exemplos estão em expansão hoje, como comprovam a popularidade de redes sociais como Facebook [...]" (LEMOS; LEVY, 2010, p. 52, grifo meu).

O texto está organizado da seguinte forma: na primeira parte apresento uma discussão sobre os usos e as reapropriações das imagens digitais pelos internautas, considerando a quantidade delas que multiplicam-se exponencialmente na rede mundial de computadores. Posteriormente, trago algumas contribuições para o campo da educação, buscando pensar as dinâmicas comunicacionais e interativas da
Web nos processos de ensinar e aprender mediados pelas imagens digitais.

\section{Imagens Digitais na Web}

\begin{abstract}
A cada dia sentimos com maior evidência o modo como a tecnologia da imagem se transformou numa prótese do olhar, sendo praticamente impossível falar da nossa existência no mundo atual sem os aparatos técnicos que acabaram por modificar a própria natureza humana (JOBIM E SOUZA, 2002, p. 75).
\end{abstract}

Vivemos nitidamente marcados pela forte presença da imagem na contemporaneidade. Estamos, a todo instante, pensando através de imagens e interagindo diariamente com grandes outdoors, pinturas, desenhos, imagens capturadas pelas lentes das câmeras fotográficas digitais e dos smartphones, imagens em movimento produzidas pela indústria cinematográfica, além de inúmeras outras. Se considerarmos que o ser humano é capaz de produzir suas próprias imagens e, ao mesmo tempo, convidar milhões de outras pessoas na Web para tecer colaborativamente novos olhares sobre estas imagens, não há como negar que a comunicação mediada pelo computador não se restringe à linguagem textual. Sobre os usos das máquinas de visão (fotografia, cinema, vídeo, internet etc.), Jobim e Souza (2011, p. 208) diz que "[...] o olhar se expande e se beneficia com o uso da técnica, pois não somos mais apenas olhados pelo outro, mas por objetos que se comunicam conosco de modo peculiar, exigindo novas maneiras de interlocução e de revelação". Isso significa estarmos atentos aos novos modos de interpretar e de recriar o mundo pela mediação dos aparatos técnicos. Mais recentemente, inúmeros aparatos técnicos vêm acessando a internet, permitindo-nos produzir e disseminar arquivos imagéticos de 
forma dinâmica a qualquer momento do dia para praticamente qualquer lugar do planeta.

Santaella (2010) mostra que, com a popularização das webcams, das câmeras digitais e dos smartphones, pessoas ao redor de todo o globo vêm produzindo uma grande quantidade de imagens, que podem ser também manipuladas em telas sensíveis ao toque, como é o caso do iPad e do iPhone. A produção da informação imagética também acelera e intensifica o diálogo em/na rede pelos internautas, sendo este "[...] um modo de produção que permite a quaisquer pessoas, não importa a idade, o gênero, a classe social, a formação, tornarem-se fotógrafos ambulantes [...]" (SANTAELLA, 2010, p. 189).

Hoje é possível que os usuários com acesso à internet possam ser produtores em potencial de informação, contribuindo para a expansão e a modificação constante da Web. De acordo com Arruda (2009, p. 19-20), "A dinâmica do mundo atual apresenta ao mundo escolar um novo paradigma a ser desvendado pelo profissional da educação e pelos estudantes - a produção de conhecimento para além da capacidade humana de acompanhamento desse". Isso porque vídeos, músicas, mensagens etc., constantemente produzidos e compartilhados pelos sujeitos, encontram-se presentes numa quantidade exponencial que dificulta selecionar o conteúdo desejado, como fica claro ao procurarmos, por exemplo, imagens da cantora Amy Winehouse ${ }^{2}$ no website do Google.

Uma busca no Google que, em 0,09 segundos, localiza aproximadamente 9.560.000 imagens da já falecida e ainda popular cantora Amy Winehouse, demonstra as potencialidades da infraestrutura do ciberespaço para propiciar

\footnotetext{
2 A minha escolha pela busca do acervo fotográfico de Amy Winehouse em 2011 no Google deu-se em função da morte da cantora neste mesmo ano, gerando muita repercussão entre os internautas na $W e b$.
}

que, com a revolução do processo de digitalização, milhões de usuários possam entrar em contato com essas e outras informações. As milhões de imagens da cantora repetem-se inúmeras vezes, mas adquirem significados diferentes na medida em que são publicadas em jornais eletrônicos, em blogs, em sites especializados em música, em sites de redes sociais da internet etc., ou seja, existe uma quantidade bastante significativa e diversa de conteúdos criados por internautas de todos os cantos do planeta a partir das milhões de imagens da cantora no ciberespaço. É a essa quantidade de informação que o jovem $\boldsymbol{B} \boldsymbol{C} \boldsymbol{B}$ se refere ao compartilhar a seguinte mensagem no Facebook: a menos que seu nome seja Google, pare de agir como se você soubesse de tudo.

A rede mundial de computadores apresenta um amplo e rico acervo multimidiático - com imagens, vídeos, sons, textos, dentre outros que permite aos usuários de todos os cantos do planeta acessar muitas fontes de informação, aparentemente inesgotáveis. Diversas comunidades do Facebook também têm nomes bastante semelhantes aos dizeres da mensagem de $\boldsymbol{B} \boldsymbol{C B}$, como a Unless your name is Google, stop acting like you fucking know everything, ${ }^{3}$ que agrega mais de 80.000 pessoas e evidencia a popularização da empresa Google nas redes sociais da internet, dona de um dos mais importantes e acessados websites de buscas atualmente. Lévy (1999, p. 106) explica que "[...] um sistema de interconexão e de pesquisa de documentos como a World Wide Web tem a capacidade de transformar a Internet em um hipertexto gigante, independente da localização física dos arquivos de computador". Sendo assim, um internauta que navega

\footnotetext{
3 Página do Facebook disponível em: <http://www.facebook com/\#!/pages/Unless-your-name-is-Google-stop-acting-like-you-fucking-know-everything/181731031885768?sk=info $>$. Acesso em: 13 set. 2011.
} 
na Europa pode usufruir dos mesmos conteúdos da Web daqueles que navegam na América Latina, e todos desfrutam de um ambiente em comum que os torna capazes de estar em contato permanente. Na mesma direção, Lemos (2009, p. 137) diz "[...] que hoje pela primeira vez nós podemos disseminar informação sob qualquer formato para qualquer lugar do planeta, sem necessariamente ter grandes recursos financeiros $[\ldots]$ ". A possibilidade que a Web apresenta para aproximar as pessoas, interconectando-as e fazendo com que haja o contato dos sujeitos com informações que são produzidas colaborativamente entre os internautas, mostra a importância de se promover uma reflexão sobre os processos de ensinar e aprender que também se expandiram para as diversas interfaces digitais.

A priori, entendo que não é possível saber de tudo pelo Google, até porque não são todas as produções culturais da humanidade, anteriores à criação da $W e b$, que se encontram digitalizadas na rede, embora bibliotecas de várias localidades do mundo, por exemplo, estejam se empenhando para propiciar que 0 acervo impresso esteja aos poucos sendo disponibilizado nos ambientes on-line para os leitores. Além disso, obras musicais de artistas e de compositores mais antigos também vêm ganhando cada vez mais espaço na rede, contribuindo para a sua constante expansão. Diante disso, creio que seja cada vez mais improvável conhecermos e desfrutarmos de todo o conteúdo disponível na $W e b$, porque nos faltaria tempo para acessar toda a memória multimidiática presente nela hoje. Para Lévy,

[...] o projeto de domínio do saber por um indivíduo ou por um pequeno grupo tornou-se cada vez mais ilusório. Hoje, tornou-se evidente, tangível para todos que o conhecimento passou definitivamente para o lado do intotalizável, do indominável (LÉVY, 1999, p. 161).

Conforme é possível perceber, Lévy (1999) já relatava, no final do século XX, ser impossível o ser humano conhecer todas as informações presentes na rede mundial de computadores. Em 2011, o Google conseguia localizar aproximadamente 9.560.000 imagens de Amy Winehouse. Com a popularização das redes sociais da internet, e dos dispositivos digitais móveis com acesso à internet, certamente a quantidade de imagens da cantora hoje é muito maior. De acordo com Primo (2013, p. 17), "O que se percebeu com a emergência das tecnologias de comunicação e informação é que a liberdade de expressão dos cidadãos pode ser potencializada via mídias digitais". Diferentemente das mídias de massa, como o rádio e a televisão, as tecnologias digitais permitem que diferentes internautas, de todos os cantos do mundo, sejam produtores em potencial de conteúdos para a $W e b$. As possibilidades e a potencialidade da rede em garantir aos internautas o acesso às inúmeras informações trazem novos desafios para o campo da educação, pois implicam em considerarmos as dinâmicas ciberculturais no ensinar e no aprender.

\section{Imagens Digitais, Redes Sociais e Educação}

Apenas para ilustrar o número de pessoas que vêm participando dos processos comunicacionais nos sites de redes sociais, Recuero (2012) mostra que em 2011 havia 800 miIhões de usuários no mundo cadastrados no Facebook e cerca de 200 milhões de usuários cadastrados no Twitter. Essa quantidade expressiva de internautas que participam dos 
recursos comunicacionais disponíveis na rede mundial de computadores não deixa dúvidas de que há uma quantidade considerável de informação que vem sendo produzida e compartilhada na Web. Segundo Lemos (2007, p. 46), os internautas podem "[...] acessar, produzir e distribuir informação, de maneira autônoma, estabelecendo redes colaborativas e processos comunicativos mais complexos", revelando a possibilidade de participação e de coautoria no ciberespaço. Isso é o que mostram Marinho et al. (2009, p. 9), ao comentar que "A Web 2.0 é a rede no tempo de uma Sociedade da Autoria, onde cada internauta se torna, além de (co) autor ou (co)produtor, distribuidor de conteúdos, compartilhando a sua produção com os demais indivíduos $[\ldots]$ ".

Pensar nas diferentes possibilidades com as quais os sujeitos utilizam as imagens digitais de Amy Winehouse é considerar também as experiências contemporâneas mediadas pelo computador, ao proporcionar interações on-line que não se restringem à linguagem textual. Isso revela novos modos de comunicar-se pelos usos das imagens que circulam pelo ciberespaço, permitindo que a informação e o entretenimento estejam constantemente sendo apresentados, produzidos e compartilhados de forma dinâmica e interativa na Web. Para Jobim e Souza (2002, p. 77-78), é imprescindível "[...] criarmos, através da educação, modos de confronto com a experiência tecnológica, colocando tanto educadores como educandos na posição de se sentirem responsáveis por inventar outras estratégias de interação na produção de conhecimento".

As imagens digitais que povoam a Web permitem que outros olhares possam ser lançados sobre o campo educacional, na tentativa de que este seja beneficiado ao conhecer os processos comunicacionais na/da internet. Ainda segundo Jobim e Souza (2002), seria interessante promover nas práticas pedagógicas novas formas de se relacionar com a tecnologia, com a possibilidade de também tornar "[...] as imagens técnicas mediadoras de um diálogo entre pessoas que buscam novos modos de narrar sua experiência, recriando o mundo na imagem e no discurso" (JOBIM E SOUZA, 2002, p. 80).

Os álbuns de fotos dos usuários nos sites de redes sociais da internet como o Facebook comprovam a popularidade dos arquivos imagéticos na Web. Alguns usuários já compartilham hoje centenas de imagens, com cada acontecimento sendo exibido e registrado na rede com muito entusiasmo. O álbum de fotos Monografia ;), criado por JS, estudante que está concluindo o curso de ciências biológicas em uma universidade da cidade do Rio de Janeiro, é interessante porque mostra $O$ andamento do trabalho da jovem pesquisadora. A legenda convidativa do álbum, Pra quem não conhece os meus amores $\wedge \wedge$, propicia que outros pesquisadores conheçam um pouco mais sobre os invertebrados marinhos, tema de seu estudo na universidade, e participem da conversa on-line no Facebook que focaliza as imagens produzidas pela jovem:

CA: ah, esse amor dá um trabalho... mas a recompensa é maravilhosa!! ;)

CA: lindas fts

CB: Lindosss. Porém as polychaetas são mais. $=P$

JS: ah q mentira! aqueles vermes nojentos haha

CB: kkkkkkkkkkkkkkkkkkkkk

BF: Filhos dão mto trabalho! São lindos, mas dão trabalho! Mamãe que o diga, né Nacelinha cuti-cuti?! Parabéns pelos rebentos, JS!! 
JS: e vc pode me dizer se ta mto ruim BF! esse negocio de balancear as cores não é comigo...

BF: JS! As fotos estão ótimas!! Mto bem!!! Acho que dá p/ mexer um detalhe ou outro, $p /$ deixar ainda melhor!! Mas nada que tenha comprometido, são só detalhes de balanço de cor e luz mesmo!! Vc tá de parabéns!!

PP: São seus os desenhos?? Outra parada... me tira uma dúvida... é normal achar tanaidacea em água doce??

JS: são meus sim. . e tem algumas spp $q$ são de agua doce sim, pq ta aparecendo $m t$ ?

Na cibercultura, podemos dialogar na/em rede, produzir e compartilhar nossas próprias imagens na $W e b$, que estarão passíveis inclusive de sofrer eventuais críticas pelos internautas que conhecem softwares capazes de editar e manipular todo e qualquer tipo de arquivo digital. Ao compartilhar suas imagens na rede, muitos internautas passam a interagir com JS para conversar também sobre seus trabalhos na universidade, promovendo um debate interessante que envolveu o desejo de todos de conhecer melhor os amores de cada um. Neste sentido, JS pôde adquirir novos parceiros de trabalho na sua investigação científica ao reconhecer que as imagens poderiam ficar ainda melhores.

Segundo Recuero (2013), as conversações em rede não deixam dúvida de que existe nos internautas o sentimento de serem legitimados e aceitos pelo outro sobre aquilo que enunciam e compartilham na internet. É a possibilidade de promover um diálogo dinâmico e participativo que faz do Facebook um espaço característico da cibercultura, no qual "[...] cada usuário é estimulado a produzir, distribuir e re- ciclar conteúdos digitais, sejam eles textos literários, protestos políticos, matérias jornalísticas, emissões sonoras, filmes caseiros, fotos ou música" (LEMOS, 2005, p. 7). Numa época em que vivemos nitidamente marcados pela presença da cultura imagética, a manipulação colaborativa das imagens digitais certamente apresenta desafios para as práticas pedagógicas.

Uma reflexão que precisa ser feita diz respeito aos modos pelos quais o aluno se constitui sujeito do conhecimento. Caberia, então, perguntar se não seria incoerente, diante da presença constante da imagem digital no cotidiano de crianças e jovens, diante das redes de conhecimento e sentidos propiciadas pelo acesso à internet, diante do movimento interativo e colaborativo presentes nessas redes, continuar mantendo em sala de aula metodologias que se fundamentam numa concepção epistemológica em que o conhecimento é trabalhado de forma linear, gradativa e individual? Para Nóvoa (1999), a escola ainda centraliza os conhecimentos no livro didático, pautando o ensino numa grade curricular rígida, tornando-se necessário romper com a mecanicidade de estratégias pedagógicas que apresentam dificuldade em dialogar com as práticas sociais mediadas pela cultura imagética.

É pelo ciberespaço que compartilhamos arquivos de diversos formatos midiáticos com outros internautas, propiciando a todos criticar, alterar e acrescentar novas informações, que serão posteriormente, e indefinidamente, compartilhadas na $W e b$, na medida em que esses arquivos circulam pelo mundo afora: um mesmo vídeo pode ser baixado de qualquer parte do planeta, passar por um processo de edição (com acréscimo de legendas, remoção do áudio e reposição de um novo etc.) e ser novamente compartilhado em uma rede social, 
por exemplo. Isso fica bastante evidente ao nos depararmos com uma imagem compartilhada no Facebook pela jovem $\boldsymbol{L} \boldsymbol{B}$, recém-formada em administração e moradora da cidade do Rio de Janeiro. Os integrantes da rede social de $\boldsymbol{L} \boldsymbol{B}$ discutem e criticam a pequena montagem digital realizada por um internauta que, com o auxílio de software de edição de imagem, recortou o corpo de uma mulher, colando-o sobre a areia da praia. A reapropriação da imagem, que recebeu a legenda Photoshop!!!! Você está fazendo isso errado!, certamente criou um momento de muita risada e diversão aos participantes da conversa a seguir:

LB: Erradíssimoooo.. rs

ALL: kkkkkkkkkk

LB: e aposto $q$ os invejosos vão dizer $q$ ela não estava na praia!

LB: $k k k k k k k k k k k k k k k k k k k k k k k k k k k k k k$ kkkkkkkkkkkkkkkkkk

ALL: Com essa foto de ótima qualidade comprovando que ela realmente estava na praia! rsrsrsrsrsrs

GS: A gigante da colina desceu! Hahh

LB: Não disse: SEMPRE tem um invejoso... deixa de ser invejoso GS, a menina foi à praia quer deixar?

GS: Guliver eh sacanagem!

A partir dos diversos conteúdos da Web somos capazes de interagir com outros usuários. Isso inclui o caso acima: a manipulação digital e o compartilhamento do resultado gráfico obtido. Em muitos casos, a imagem manipulada pode adquirir muita popularidade, sendo visualizada por milhões de pessoas que certamente discutirão e avaliarão o trabalho do internauta, como ficou claro na legenda adicionada à imagem: Photoshop!!!! Você está fazendo isso errado!. A partir do desenvolvimento tecnológico hoje, a produção colaborativa e distributiva da informação adquire centralidade, com a participação bastante intensa dos internautas no compartilhamento de impressões e eventuais críticas, com o objetivo também de que sejam discutidas formas de aprimorar o trabalho do outro. Muitas das vezes isso pode provocar risadas e descontrações entre os internautas, como quando o jovem $\boldsymbol{A} \boldsymbol{L} \boldsymbol{L}$ falou ironicamente sobre a imagem da mulher na praia: Com essa foto de ótima qualidade comprovando que ela realmente estava na praia! rsrsrsrsrsrs. $\mathrm{Na}$ conversa on-line, os usuários avaliaram que o trabalho de edição de imagem foi ruim, com GS fazendo menção ao personagem Gulliver, ${ }^{4}$ pelo fato de a mulher estar desproporcional ao restante do cenário: Guliver eh sacanagem!. Para Lemos e Lévy (2010, p. 76-77), a conexão com a internet vem proporcionando "[...] possibilidades de acesso a pontos de vista de um conjunto de atores em debate ou em conflito. Mais ainda, pode-se produzir uma visão de mundo independente e distribuí-la livremente $[\ldots]^{\prime \prime}$.

O ciberespaço é capaz de agregar diversos pontos de vista com a intenção de dar-se a conhecer, possibilitando que os internautas teçam colaborativamente novos saberes, participem da criação de vínculos afetivos e de novas formas de sociabilidades entre os pares. E para que isso ocorra, os bits de informações que circulam livremente pela Web são imprescindíveis para o encontro com o outro - um encontro cada vez mais mediado pelas imagens digitais que promovem formas outras de ensinar e aprender. Para Santaella (2013, p. 45), a cultura digital instaura "[...] uma cultura participativa, onde cada um conta e todos

\footnotetext{
${ }^{4}$ Uma descrição da obra As Viagens de Gulliver, escrita pelo inglês Jonathan Swift, pode ser encontrada em: <http:// pt.wikipedia.org/wiki/As_Viagens_de_Gulliver.> Acesso em: 7 fev. 2012.
} 
colaboram, portanto, uma cultura integrativa, assimilativa, cultura da convivência que evolui de acordo com as exigências impostas pelo uso dos participantes".

Uma coisa é certa: o ciberespaço rompe com a linearidade, com as práticas verticais de saberes, nos colocando diante de um "[...] hipertexto mundial interativo, onde cada um pode adicionar, retirar e modificar partes dessa estrutura telemática, como um texto vivo, um organismo auto-organizante [...]" (LEMOS, 2013, p. 123). Uma das grandes vantagens da Web 2.0 é a facilidade de acesso às informações, além do compartilhamento de arquivos e da ressignificação desses pelos usuários, que tornam-se colaboradores numa parceria que propicia a aprendizagem na/em rede (OKADA, 2011). Dessa forma, a manipulação das imagens digitais reconfigura a forma como aprendemos-ensinamos porque rompe com a hierarquia do saber e horizontaliza a relação com o outro na produção do conhecimento.

\section{Práticas Pedagógicas e Imagens Digitais: algumas palavras finais}

As experiências mediadas pelas tecnologias digitais em rede reconfiguram a forma como recebemos informação e produzimos conhecimento na relação com o outro. Para Lévy (1999, p. 94, grifo do autor), quando estamos conectados é possível "[...] não apenas ler um livro, navegar em um hipertexto, olhar uma série de imagens, ver um vídeo, interagir com uma simulação, ouvir uma música gravada em uma memória distante, mas também alimentar essa memória com textos, imagens etc.". Rosa, Ferreira e Oswald (2010, p. 223) seguem nessa mesma direção e destacam que "[...] a quantidade de jovens que vêm constituindo novas sociabilidades através de maneiras híbridas de relacionar-se no virtual, é um indicativo de mudanças culturais que merecem um olhar mais cuidadoso". Diante disso, reinventar as práticas pedagógicas à luz das dinâmicas da cibercultura é cada vez mais necessário e, ao mesmo tempo, se torna uma possibilidade concreta, na medida em que os aparatos tecnológicos vêm se popularizando na vida cotidiana dos sujeitos, proporcionado o estreitamento dos vínculos sociais. Defendo que um dos caminhos para isso seria descobrir as potencialidades desses aparatos nos processos comunicacionais contemporâneos, que abarcam o desejo e a necessidade dos usuários de se sentirem como produtores de cultura.

Reinventar essas práticas pedagógicas é mais do que a mera implementação das mídias digitais na sala de aula, é reconhecer e legitimar outras formas de aprender; um aprender que se constitua à luz nas dinâmicas do compartilhamento, da colaboração na/em rede com outros internautas. Concordo com Santos (2002, p. 119), quando diz: "Não basta apenas inovar a forma nem o conteúdo dos materiais ou estratégias de ensino. É necessário transformar o processo de comunicação dos sujeitos envolvidos". Isso não significa desvalorizar ou inutilizar determinadas tecnologias que ainda são bastante utilizadas nas práticas pedagógicas, como o quadro-negro, o livro didático, o retroprojetor, dentre outros, mas promover novas formas de entrar em contato com os conhecimentos.

Se é possível encontrarmos e aprendermos colaborativamente sobre uma quantidade significativa de assuntos acadêmicos e não acadêmicos, como as informações consumidas e produzidas pelos internautas estariam modificando as dinâmicas do ensinar e do aprender 
na contemporaneidade? Como as interfaces digitais poderiam ressignificar as práticas pedagógicas que ainda são calcadas em uma perspectiva de mera transmissão do conhecimento, desconsiderando a dinâmica colaborativa e interativa das redes digitais na produção dos saberes? Como as imagens digitais poderiam ser incorporadas nos processos educacionais, criando nos estudantes o desejo e a necessidade da produção e emissão de novos saberes?

As reflexões tecidas ao longo do trabalho apontaram para algumas questões centrais sobre os usos das imagens digitais nos processos comunicacionais na/da internet, buscando contribuições para o campo educacional. Longe de buscar respostas prontas e supostamente verdadeiras/definitivas, optei neste texto pela formulação de algumas perguntas finais que revelam minha preocupação com a reconfiguração das formas de ensinar e aprender que emergem na relação das pessoas com a cultura digital. Essa preocupação certamente não permite que nós, enquanto educadores, "[...] fiquemos à janela vendo a banda passar [...]" (SANTAELLA, 2013, p. 46), mas que estejamos implicados nos desafios que o tempo presente nos traz.

\section{Referências}

AMARAL, A. Autonetnografia e Inserção Online: o papel do "pesquisador-insider" nas práticas comunicacionais das subculturas da Web. Revista Fronteiras: estudos midiáticos, São Leopoldo, v. 11, n. 1, p. 14-24, jan./abr. 2009.

AMARAL, A.; NATAL, G.; VIANA, L. Netnografia Como Aporte Metodológico da Pesquisa em Comunicação Digital. Revista FAMECOS, Porto Alegre, n. 20, p. 34-40, dez. 2008.

ARRUDA, E. Relações Entre Tecnologias Digitais e Educação: perspectivas para a compreensão da aprendizagem escolar contemporânea. In: FREITAS, M. (Org.). Cibercultura e Formação de Professores. Belo Horizonte: Autêntica Editora, 2009. P. 13-22.

COUTO JUNIOR, D.R. Etnografia Virtual e as Contribuições de Mikhail Bakhtin na Pesquisa com Internautas. Revista Teias, Rio de Janeiro, v. 14, n. 31, p. 83-94, maio/ago. 2013.

GUTIERREZ, S. A Etnografia Virtual na Pesquisa de Abordagem Dialética em Redes Sociais On-line. In: REUNIÃO ANUAL DA ASSOCIAÇÃO NACIONAL DE PÓS-GRADUAÇÃO E PESQUISA EM EDUCAÇÃO, 32. 2009, Caxambu. Anais... Caxambu: Espaço Livre, 2009.

JOBIM E SOUZA, S. O Olho e a Câmera: desafios para a educação na época da interatividade virtual. Revista Advir, Rio de Janeiro, n. 15, p. 75-81, set. 2002. 
JOBIM E SOUZA, S. Por uma Epistemologia da Imagem Técnica. Pesquisas e Práticas Psicossociais, São João del-Rei, v. 6, n. 2, p. 206-210, ago./dez. 2011.

LEMOS, A. Ciber-cultura-remix. Artigo escrito para apresentação no seminário "Sentidos e Processos" dentro da mostra "Cinético Digital", no Centro Itaú Cultural, São Paulo, agosto de 2005, p. 1-9. Disponível em: <http://www.facom.ufba.br/ciberpesquisa/andrelemos/remix.pdf> Acesso em: 17 ago. 2011.

LEMOS, A. Cibercultura Como Território Recombinante. In: MARTINS, C.; CASTRO E SILVA, D.; MOTTA, R. (Org.). Territórios Recombinantes: arte e tecnologia: debates e laboratórios. São Paulo: Instituto Sérgio Motta, 2007. P. 35-48.

LEMOS, A. Infraestrutura Para a Cultura Digital (entrevista). In: COHN, S.; SAVAZONI, R. (Org.). Cultura digital.br. Rio de Janeiro: Beco do Azougue, 2009. P. 135-149.

LEMOS, A. Os Sentidos da Tecnologia: cibercultura e ciberdemocracia. In: LEMOS, A.; LÉVY, P. O Futuro da Internet: em direção a uma ciberdemocracia planetária. São Paulo: Paulus, 2010. P. 21-31.

LEMOS, A. Cibercultura: tecnologia e vida social na cultura contemporânea. 6. ed. Porto Alegre: Editora Sulina, 2013.

LEMOS, A.; LÉVY, P. O Futuro da Internet: em direção a uma ciberdemocracia planetária. São Paulo: Paulus, 2010.

LÉVY, P. Cibercultura. Tradução de Carlos Irineu da Costa. São Paulo: Ed. 34, 1999.

MARINHO, S. et al. Oportunidades e Possibilidades Para a Inserção de Interfaces da Web 2.0 no Currículo da Escola em Tempos de Convergências de Mídia. Revista e-Curriculum, São Paulo, v. 4, n. 2, p. 1-28, jun. 2009.

MARTINS, D.M.; COUTO JUNIOR, D. Jovens Jogadores de Videogames e Produção de Sentidos: contribuições para se pensar práticas educativas alteritárias. In: REUNIÃO ANUAL DA ASSOCIAÇÃO NACIONAL DE PÓS-GRADUAÇÃO E PESQUISA EM EDUCAÇÃO, 30., 2007, Caxambu. Anais... Caxambu: Espaço Livre, 2007.

MERCADO, L. Pesquisa Qualitativa On-Line Utilizando a Etnografia Virtual. Revista Teias, Rio de Janeiro, v. 13, n. 30, p. 167-181, set./dez. 2012.

NÓVOA, A. Os Professores na Virada do Milênio: do excesso dos discursos à pobreza das práticas. Educação e Pesquisa, São Paulo, v. 25, n. 1, p. 11-20, jun. 1999. 
OKADA, A. Colearn 2.0: coaprendizagem via comunidades abertas de pesquisa, práticas e recursos educacionais. Revista e-curriculum, São Paulo, v. 7, n. 1, p. 1-15, abr. 2011.

OROFINO, M. I. Mídias e Mediação Escolar: pedagogia dos meios, participação e visibilidade. São Paulo: Cortez, 2005.

PRETTO, N. Personagem de 2011: o ativista. In: REFLEXÕES: ativismo, redes sociais e educação. Salvador: EDUFBA, 2013. P. 65-66.

PRIMO, A. Interações Mediadas e Remediadas: controvérsias entre as utopias da cibercultura e a grande indústria midiática. In: PRIMO, A. (Org.). Interações em Rede. Porto Alegre: Ed. Sulina, 2013. P. 13-32.

RECUERO, R. A conversação em Rede: comunicação mediada pelo computador e redes sociais na internet. Porto Alegre: Sulina, 2012.

RECUERO, R. Atos de ameaça à face e à conversação em redes sociais da internet. In: PRIMO, A. (Org.). Interações em rede. Porto Alegre: Editora Sulina, 2013. p. 51-69.

ROCHA, P.; MONTARDO, S. Netnografia: incursões metodológicas na cibercultura. Revista E-Compós, Brasília, v. 4, p. 1-22, dez. 2005.

ROSA, A.; FERREIRA, H.; OSWALD, M. L. Práticas Culturais Juvenis: máscaras contemporâneas. Revista da FAEEBA, Salvador, v. 19, n. 33, p. 215-227, jan./jun. 2010.

SANTAELLA, L. A Crítica das Mídias na Entrada do Século 21. In: PRADO, J. (Org.). Crítica das Práticas Midiáticas: da sociedade de massa às ciberculturas. São Paulo: Hacker Editores, 2002. P. 44-56.

SANTAELLA, L. A Ecologia Pluralista da Comunicação: conectividade, mobilidade, ubiquidade. São Paulo: Paulus, 2010.

SANTAELLA, L. Intersubjetividade nas Redes Digitais: repercussões na educação. In: PRIMO, A. (Org.). Interações em Rede. Porto Alegre: Ed. Sulina, 2013. P. 33-47.

SANTOS, E. Formação de Professores e Cibercultura: novas práticas curriculares na educação presencial e a distância. Revista da FAEEBA: educação e contemporaneidade, Salvador, v. 11, n. 17, p. 113-122, jan./jun., 2002.

SANTOS, E. A Cibercultura e a Educação em Tempos de Mobilidade e Redes Sociais: conversando com os cotidianos. In: FONTOURA, H.; SILVA, M. (Org.). Práticas Pedagógicas, Linguagem e Mídias: 
desafios à Pós-graduação em Educação em suas múltiplas dimensões. Rio de Janeiro: ANPEd Nacional, 2011. P. 75-98.

SANTOS, R.; COUTO JUNIOR, D. Etnografia Virtual e os Estudos com os Cotidianos: a tessitura do conhecimento em rede. Revista EducaOnline, Rio de Janeiro, v. 7, n. 1, p. 22-39, jan./abr. 2013.

Submetido para avaliação em 08 de abril de 2014.

Aprovado para publicação em 02 de janeiro de 2015.

Dilton Ribeiro do Couto Junior - Universidade do Estado do Rio de Janeiro, Rio de Janeiro, BR-RJ. E-mail: junnior_2003@yahoo.com.br 